\title{
Information Needs and Experiences of Scholars in Women's Studies: Problems and Solutions
}

\section{Lynn Westbrook}

\begin{abstract}
Women's studies faculty often engage in complex information-seeking patterns as they examine social issues from a variety of disciplinary and theoretical perspectives. Academic librarians constructing an understanding of those patterns in order to provide effective reference service can incorporate the results of this national, qualitative study on the information needs, information uses, successful strategies, productive tactics, and problem issues reported by a wide range of these interdisciplinary scholars. Finally, advice and guidance from forty-two women's studies librarians in a wide variety of academic settings provide an array of practical tools for serving this complex population.
\end{abstract}

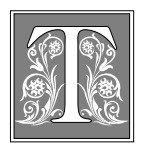

he increasing number of faculty whose research involves multiple disciplines offer a complex service challenge to academic librarians in the areas of reference, instruction, and document delivery. ${ }^{1}$ Librarians serving these scholars draw, in part, on the growing user-needs research literature to directly inform their service provision decisions. This is the second of two reports on the findings of a national study of information-seeking patterns within, and service techniques used for, one such population, women's studies faculty. ${ }^{2}$

\section{Background}

At its most complete, the interdisciplinary analysis of a research problem requires the use of a variety of appropriately selected theoretical perspectives, research literature, raw data, and domain knowledge. Even faculty educated in the use of interdisciplinary search tactics, an uncommon preparation, can easily find themselves required to identify experts, determine the validity of sources, follow discourse analysis, and otherwise critically examine artifacts of, and elements in, a field for which they have relatively little formal preparation. The rise of interdisciplinary research in higher education continues unabated as the complexities of in-depth analysis demand greater openness in theory generation.

None of this cross-disciplinary work is new, but the level of flexibility is growing. The sciences continue to splinter and

Lynn Westbrook is an Associate Professor in the School of Library and Information Studies at Texas Woman's University; e-mail: jwestbrook@twu.edu. This study drew on qualitative data from 215 faculty members and 42 librarians involved in women's studies. Their insights into information-seeking problems and strategies provide useful background that should support the ongoing work of reference and instruction librarians who serve this complex community of interdisciplinary scholars. 
reform, creating connections such as those between chemical biology and quantum physics. The humanities, pushed by socially constructed analytic frameworks, blur various lines such as those between ethnic studies and literature. The social sciences, long on the cutting edge of interdisciplinary analysis, examine social problems, such as the feminization of poverty, by weaving together contextual threads from fields as disparate as economics, law, education, urban studies, government policy, and communication. With degrees in interdisciplinary areas increasingly available in higher education, librarians will continue to serve undergraduates, graduate students, and faculty who view their work through the multiple lenses of different academic specialties and theories.

\section{Research Problem ${ }^{3}$}

Current research indicates that interdisciplinary scholars differ from their singlediscipline colleagues in information-seeking strategies and patterns. ${ }^{4}$ They may use multiple interpersonal networks, expend significant resources in crossing boundaries, and struggle with inadequate periodical indexing. ${ }^{5-7}$ The effort to construct meaning and develop understanding across traditional theoretical boundaries may require forays into unfamiliar subject domains. ${ }^{8}$ The use of cross-disciplinary databases requires the use of multiple strategies and search terms appropriate to both the controlled vocabulary and the natural language of each field. ${ }^{9}$ Interdisciplinary scholars' patterns of information seeking, search strategies, and search problems remain relatively unexplored.

For academic librarians committed to meeting the information needs of these scholars, the research problems continue to center on development of a deep understanding of these patterns, strategies, and problems. Placing these research problems within the context of the women's studies (WS) community supports effective progress in understanding interdisciplinary information needs be- cause WS faculty have had ties to many academic disciplines for more than three decades and the field's resources are quite well developed..$^{10}$

\section{Literature Review}

A review of the literature on interdisciplinary information needs and the reference services designed to meet those needs covers a range of academic disciplines and specific services. Although an information-needs analysis of a particular subpopulation at a single institution is necessary to design local services that meet specific needs, an overarching review of key issues provides a worthwhile background for this study.

Interdisciplinary information needs are rooted in the concept of scatter. ${ }^{11}$ "Scatter" is a measure of the number and structure of the resources in an academic discipline. Traditional academic disciplines are tightly defined with a relatively small number of professional organizations, scholarly journals, heavily used reference tools, and periodical indices. Learning to navigate the resources of a traditional discipline requires learning the language of its indexers (controlled vocabulary), the language of its scholars (natural language), and the structure of its component parts. A solid graduate education suffices for most of this effort because the resources are not widely dispersed in these "low-scatter" fields.

In contrast, interdisciplinary fields such as women's studies are considered "highscatter" fields in that a wide array of resources is frequently needed to gather relevant information from professional organizations' publications, established reference works, major periodicals, and an appropriate array of periodical indices. Examination of the feminization of poverty, for example, could require use of the major periodical indices in WS as well as Public Affairs Information Service, Social Science Citation Index, Economic Abstracts, and more. For each index, the appropriate background tools (e.g., specialized encyclopedias, handbooks, and dictionaries) might be needed to identify critical theory, 
subject experts, key readings, and terms. Within each index, the indexing terms are likely to differ on both organizational and conceptual lines whereas the natural language used in article titles and, where available, abstracts will reflect the perspective of the authors' home disciplines. The learning curve on interdisciplinary research is, obviously, related to the degree of scatter encountered in the work.

Academic librarians have served women's studies since the 1970s with all the tools of the profession. Recognizing the complex information needs of these interdisciplinary scholars, librarians have created substantial reference bibliographies, strengthened subject access, devised online search strategies, developed collections, and provided reference and instructional service. ${ }^{12-16}$ Most of this work builds on a few finite research studies (such as examinations of subject headings ${ }^{17}$ ) and praxis. ${ }^{18}$

\section{Research Question}

As a small contribution to the support of academic librarians' efforts to serve interdisciplinary scholars and given the generous support of the Carroll Preston Baber Research Award, this study progresses toward a more complete understanding of the information needs and search experiences of WS scholars. Building on earlier work, this research design required a diverse set of participants to answer both neutral and open-ended questions. ${ }^{19}$ Progress on the following two questions was discussed in the ACRL conference paper mentioned earlier:

- What library services do WS faculty use in their research and teaching?

- What information resources do WS faculty use in their research and teaching?

A set of twenty services and resources was offered to respondents in a series of three questions as one part of a substantial questionnaire.

This article reports the second segment of the study by examining the following research questions:

- What do WS faculty consider their most productive patterns of academic library use?
- What problems do WS faculty encounter when using libraries?

- At which research stages would what type of information support be most useful to WS faculty?

- What strategies do WS librarians use and/or recommend to their colleagues in the design of services for WS faculty?

These four research problems comprise this second report from this study's broader examination of WS faculty's information-seeking strategies and information needs in the context of the research process.

\section{Data Gathering ${ }^{20}$}

To understand the data-gathering technique, an initial understanding of the population's nature is required. The study's population, women's studies scholars, is amorphous in the extreme. WS programs range along a formality continuum from degree-granting departments with line-item faculty assigned on a full-time basis down to a simple array of course offerings labeled as WS with no formally assigned faculty beyond the part-time or nominal program director. Faculty may be: affiliated, part-time, or full-time; teach a single course on an irregular basis or devote all of their efforts to the field; join the National Women's Studies Association (NWSA) and/or hold memberships in their "home" discipline organization.

Gathering a substantial amount of indepth data from so diverse a population required the triangulation of several different contact methods and the use of a written questionnaire. Because this study was intended as an open exploration rather than a quantitative analysis, the entire population was approached rather than a random sample selected. Scholars received word of the study through three structured methods as well as one spinoff method. The structured methods were:

- written questionnaires sent by postal mail to every individual member of the National Women's Studies Association; 
- four invitations to participate in the study sent to the primary discussion list for WS (WMST-L) over a five month period with respondents receiving the questionnaire via their preferred communication mechanism (i.e., electronic mail or postal mail) ${ }^{21}$;

- postal mail copies of the questionnaire sent, with two follow-up mailings, to the chairs of every U.S. program offering anything more than isolated undergraduate courses in women's studies with a request to share the instrument with all WS faculty.

The spin-off method developed from the NWSA's decision to print a participation solicitation for the faculty portion of the study in their newsletter..$^{22}$

The questionnaire developed from research questions raised by previous research in this field, including research by Marcia Bates, Kristin Gerhard et al., and Lynn Westbrook. ${ }^{23}$ Initial discussion of the research questions led to an instrument draft that was pretested on seven WS scholars around the country. Chosen for their diverse interests, university sizes, and geographic locations, these scholars quickly returned the completed questionnaires with useful data and productive commentary on the instrument. Minor, but useful, changes were made in the layout and wording before the initial distribution.

This methodology was limited by four factors. First, those who chose to respond were self-selected and may therefore have a higher interest in, commitment to, or awareness of the relationship between academic library service and their own information seeking. Second, the respondents were not intended to form a statistically accurate representation of the whole population, particularly in light of all the population variables, such as size of institution, home discipline, and academic rank. That, of course, was anticipated in the whole approach to this work, but the rich data revealed by the study must not obscure this basic fact. Third, although WS scholars exemplify many aspects of interdisciplinary scholarship, they do not represent all interdisciplinary scholars. What is learned herein may have only limited transference to other fields. Fourth, the questionnaire demanded a good deal of thought from the study participants. Although this almost certainly lowered the response rate, those who did participate provided rich data. Given those limitations, however, this study provides substantial information for academic librarians serving this complex population.

In total, 215 viable questionnaires were returned, 70 via e-mail and the rest via postal mail. ${ }^{24}$ The many variables within the community were well represented: rank, program type, geographic location, tenure status, department affiliation, and WS affiliation. The rich variety among each of these variables increases the value of these data. For example, 42 percent of the respondents who reported their rank were full professors and 33 percent were associate professors, lending the weight of their experience in the study. ${ }^{25}$ Of the 537 programs offering anything more than isolated undergraduate courses in WS, 168 (31\%) were represented in this study. Thirty-seven percent of the respondents were from programs with a minor, and 30 percent were from programs that offered some level of graduate work in women's studies. Of course, the program level does not necessarily correlate with the size of the parent institution, but it could relate to the level of library support that faculty might reasonably expect or librarians might be funded to supply. Of the forty-nine states with WS programs, forty-four were represented by respondents. Of the 154 respondents who reported their tenure status, forty-two $(27 \%)$ were either pretenure or had tenure pending. The vast majority of respondents, 185 , reported a non-WS affiliation and thirtythree of those reported a second, non-WS affiliation. The single largest disciplinary affiliation was with English, followed by sociology, history, psychology, and political science. Dividing the affiliations into social sciences, humanities, and natural sciences produces the long-established 
emphasis on the humanities (50\%) and social sciences (45\%), with minor representation of the natural sciences $(5 \%) .{ }^{26} \mathrm{Fi}$ nally, 119 respondents (55\%) reported a formal affiliation with WS. Those who had no such ties still considered their teaching and/or research tied to the field. This is common among WS scholars who take gender as a critical variable or lens in their research while remaining academically assigned to their traditionally established departments. The diversity in responses from such a wide range of academic ranks, program types, tenure-status levels, geographic locations, and disciplines strengthens the value of the responses by more thoroughly identifying the spectrum of possible informationseeking contexts.

The final segment of the study solicited data from academic librarians serving WS scholars with contact established via the Women's Studies Section (WSS) of the ALA and WMST-L. The WSS graciously included a participation solicitation in its newsletter and discussion list contacts (both WMST-L and WSS) provided the other conduits to this group of practitioners. ${ }^{27}$ Forty-two librarians from different institutions generously shared their exemplars, suggestions, and recommendations for meeting the needs of WS scholars.

\section{Data Analysis}

The open-ended questions and comment areas of the questionnaire generated a wealth of examples and explanations of information-seeking experiences among WS faculty. All of these statements were transcribed or, in the case of e-mail responses, pasted into word-processed data files. Using HyperResearch to record the gradual development of directional coding categories as prescribed by the constant comparison method of content analysis, a set of codes was developed and applied to all of the data. ${ }^{28}$ After all of the codes had been fully developed, the data were reviewed to ensure consistent application of the codes. These codes were "directional" in that they indicated not only content (e.g., Internet use), but also content direction (e.g., heavy Internet use versus no Internet use). Most of the 430 directional codes were then grouped into nine broad patterns. As explained earlier, these emergent patterns are no more empirically valid than the respondents are statistically representative of the whole population, but they are meant to deepen understanding, not quantify experience. These qualitative findings do suggest some viable approaches for supporting the work of WS scholars.

\section{Faculty Findings}

This set of findings falls into four areas: use of library services, stages at which library services are useful, problems in information seeking, and productive strategies in information seeking. In some of the discussions below, the percentage of respondents who noted a particular point will be reported. Keeping the qualitative nature of these data firmly in mind, the inclusion of these numbers is offered only as another piece of context in which to examine the findings. Points made by only a few respondents may yield the most fruitful clues for service initiatives, and extremely common points still do not represent a statistically valid random sample of the population's information needs. Nevertheless, the percentages add to context and are offered on that basis alone.

\section{Reports of Library Service Use}

Faculty reported that librarians had successfully helped them solve information problems in the following broad areas: getting physical materials, getting information, doing research in general, learning to do research, and working with students. As the following exemplary quotations indicate, many of these scholars are used to working closely with librarians. ${ }^{29}$

- Getting physical materials: "Often I read about a document in, for example, the newspaper, and ask the government documents librarian to get it for me."

- Getting information: "[They helped me find] a reference I had lost. It's like 
magic. With little information, they find things!"

- Doing research in general: "When I venture into a new field, such as looking for current work on emotions in [field], I have gotten good advice and assistance."

- Learning to do research: "I consult librarians to learn sources of information available when doing a project. As new technology comes on, I ask for assistance in learning to use it correctly so I'm not always bugging the librarian about them."

- Working with students: "I have requested librarians to give my students instruction in research methods and resources. They are excellent with classes."

Each of these five categories, of course, contained numerous specific subcategories of which some of the more common are noted below:

- Getting physical materials: Help with interlibrary loan; help get materials (mentioned by 53 respondents); help get AV material; help get primary material;

- Getting information: Help complete a citation; help find simple facts (56);

- Doing research in general: Help with database use (56); help with Internet use; help use new services and resources;

- Learning to do research: Help learn library databases; help learn to find information in general;

- Working with students: Help students with user education; help students with reference.

In only a few cases have personal relationships been established with librarians who become valued resources. Nevertheless, a number of respondents rely on the instructional and facilitator roles in which academic librarians are well versed.

\section{Reports of the Stages at Which Library Service Is Needed}

Faculty information seeking could be envisioned as a continuum experience. At the broad end of the continuum is ongoing, open-ended, generalized gathering, identifying, and receiving of information that might spark an idea, fill a specific need, or simply support an ever-shifting research and teaching agenda. Alternatively, the narrow end of the continuum consists of goal-specific, focused efforts in which information is gathered, identified, received, and even actively sought in order to make progress on a finite project such as a class, book, article, or conference presentation. In between the two ends of the continuum lie experiences that serve both needs to some extent. With an emphasis on the narrow end of the continuum in particular, one segment of the questionnaire asked respondents to characterize the type of help they needed at the beginning, middle, and end of their projects.

Results indicate that in the early stages of work, concrete support in exploring the issue at hand would be most helpful. That support may take the form of identifying appropriate tools or interlibrary loans. Sixty-two respondents mentioned general exploration as valuable whereas several other specific support services were mentioned by a few individuals, including such items as starting an initial literature review ("I do lit searches in the early stage of a project mostly, but also throughout"), exploring new databases, and help in simply identifying resources available on the topic ("I need support in the beginning, where I'm figuring out what kinds of information are available, what library resources I've never used before that might help, what's new, what's current").

During the working stages, after a project has been launched, the following support mechanisms became critical: help finding specific, finite pieces of information (104), ("I definitely need librarians during the 'gathering specific info' phase, when I've exhausted my own more general tools and still can't find exactly what I'm looking for"), help with the literature review (88), and help in gathering background information (83). Thirty participants noted that ongoing work could also benefit from library support. Other support services were mentioned by fewer people, including help in physically gathering sources, learning to use a database, and document delivery. 
During the final stages, as a project moves toward completion, less library support is needed, but aid in checking citations for content, accuracy, and format is highly valued. ("The most critical stage is in prepping a manuscript for publication. Inevitably, the copy editor has given an unrealistically short time line to check citations, verify statistics, etc. The urgency makes library support crucial.") For some participants, making sure that no gaps exist in the literature gathered earlier is essential. ("Later, making sure something crucial didn't come out while I was working on the project.") Document delivery ("interlibrary loan: wonderful service, allowing me to do research and writing at home") and fact gathering were the two services mentioned as important at all stages of work.

\section{Reports of Problems in Information Seeking}

A number of concerns, problems, barriers, and difficulties were reported in research, general information seeking, library use, and keeping up with relevant literature. These reports fit loosely into three broad groups: problems with information resources, with libraries, and with themselves.

\section{Problems with Information Resources}

The many information-resource problems fit into six general subcategories: information is hard to find and use; information is of poor quality and coverage; information is of limited quantity; information on the Internet is unsatisfactory; information's interdisciplinarity is difficult; and information is overabundant $^{30}$

- Information is hard to find and use.

- "Information on activism included in alternative presses' newsletters and local organizational materials is hard to come by. We need women's studies archives on feminist activism."

- Information is of poor quality and coverage:

- "I am more concerned about the limits of a resource than about my ability to use it properly. My bibliographic skills are strong, and I have been well trained in judging the appropriateness of resources to my research needs. And electronic resources are problematic; computers go down; material can't be read, etc. Very frustrating."

- "I find most databases and indexes lag too far behind the publication date to be useful for my writing. In women's studies, what was published last year is often more important than the best article from the 1980s."

- Information is of limited quantity.

- “One problem, a major one, is getting books out of print. I have to Xerox too much material."

- Information on the Internet is unsatisfactory.

- "Web is very confusing, lots of junk, takes too much time to wade through it all."

- "I still find using Web resources a bit frustrating. Often I can't get online when I need to, and I can't always locate really helpful sites."

- Information's interdisciplinarity is difficult.

- "I have so many fields that I have despaired of keeping up in any of them; I do interdisciplinary work in several fields. 'Keeping up' in the way that discipline-specific folks do is impossible."

- "One problem is that my work is at the intersections-women, work, state, political economy, family-so I have to try to keep up on everything, and I don't have a sense how to organize the materials, especially being in an interdisciplinary field."

- Information is overabundant.

- "There is too much good material being published in the field, though a lot of it goes out of print too soon."

- "It always seems there is so much to know and keep up with and that similar work gets done in different fields and under different words. The easy access to information is often more frustrating than in the old days of SCCI and bound literature search materials."

From a librarian's perspective, of course, the increased production in WS 
indices, journals, monographs, conference proceedings, and Web sites is offset by the continuing gaps in indexing, the short book runs, ongoing recovery work, and inadequate statistical resources. An understanding of the field's structure can only be developed in the context of its relationship to other academic disciplines. Helping faculty develop the mental models that allow them to navigate resource inadequacies should be quite productive.

\section{Problems with Library Information}

It is worth noting that fifty-three respondents mentioned that they actually avoid librarians, primarily on the theory that scholars are totally responsible for and/ or quite capable of handling their own information needs. Others, primarily those from teaching institutions, pointed out that their librarians are only funded, staffed, and responsible for helping students.

\section{Our librarians are strictly committed to aiding us in our teaching respon- sibilities and would probably con- sider it beneath them to aid teaching faculty ... with research/writing/ publishing. At the very least, it would be low priority for them.}

Others note different barriers, such as the following: "When I do consult a librarian, I often find I can't speak their language and express what I am looking for so I usually come upon it on my own," "It never occurred to me a librarian would/could help," and "Our library is so understaffed that I seldom ever speak to a librarian."

In addition to general complaints about their libraries ("My most common concern with resources is the inadequacy of the library"), participants reported problems with collections and staff. Collections and resources generally lacked funding and that was recognized as the core problem, rather than librarians unwilling to expend funds on WS materials and services. Comments on library and resource problems included the following:
- Getting to the electronic collections: "We keep changing access to databases, and I keep having to reestablish connection, get new codes, etc., to do research."

- Getting to journals: "We have very few WS research journals. Anymore I order things by ILL, but it would be better if I could browse more."

- Getting to books: "My college library buys so few current books; the WS budget for books is $\$ 100$ per year."

- Getting to reference resources: "I wish a service like CARL-Uncover were paid for by my library."

- Getting properly funded collections in general: "Frankly, I'm at a VERY small school with very limited library resources. Our librarians do a good job with their resources, but they're mainly working on teaching resources. Our library is grossly underfunded, and librarians can't bring materials out of the air."

Library staff information problems are rooted in service management, LIS education, and proper reference interview techniques.

- Service management

- "I can never find a librarian free to help me."

- "The interlibrary loan people are sometimes less than helpful in explaining why they have a hard time locating obscure sources, so that I don't know whether some library has something and isn't willing to lend it or just doesn't have it. I call up and go to other archives, without them."

- "Really, I haven't relied much at all on our library staff. They seem either overworked or distracted."

- "I have observed some librarians at reference desks who spend the day reading. They will only assist patrons when asked and they rarely initiate contact with patrons. Several times they have assisted me with little enthusiasm. I attribute this to their being burned out, not to a lack of knowledge."

- LIS education

— "Libraries should put more time into training librarians to sort out the trash on 
the net, so that instead of saying, 'Oh try this page from the German grad students at UCLA, they list a lot of links,' and then it turns out that the page hasn't been updated for two years and stuff is no longer extant, etc. They can evaluate what's on the Web, just as they do when books are purchased."

- "When my needs have been more specific, when I've needed to come up with some specific terminology to help my searches by computer or through the stacks, the librarians have been less helpful. They did not seem well informed in the specific field of women's studies or feminist studies, though they were always open to trying (in other words, the problem was not a matter of attitude but of education, I believe)."

- Reference interview techniques

- "I often am frustrated by librarians who repeat back to me as suggestions steps I've just told them I've already taken."

— "When I do consult a librarian, I often find I can't speak their language and express what I am looking for, so I usually come upon it on my own."

- "I need a journal search for an article on gender theory. The librarian wasn't coming up with much I could use. When we talked things over, it turned out that she was searching only social science databases (reasoning that I was a social scientist), whereas I needed to review humanities-based research as well for this interdisciplinary project."

A focus on solving information problems, rather than fulfilling information requests, would help ameliorate many of these concerns.

\section{Problems with Self}

Problems with their own information work fell into three broad categories: actually doing and keeping up with research; learning how to do and keep up with research; and managing information when they had it.

- Doing and keeping up with research

-Handling the load of interdisciplinary work: "I (and everyone else, I sus- pect) feel absolutely unable to keep up with work in my field. I can track all articles in my most narrowly defined field, but from that 'center,' my sense of my competence drops precipitously."

-Searching fully and accurately: "A lot of the resources I need could be in three different databases. I worry that I might miss something."

-Choosing what to search: "Appropriateness to the topic, whether it is worth consulting that resource for useful information or not."

-Keeping up with the field: "Increasingly, I need more 'THIS YEAR'S WORK IN THE FIELD' type of summaries, but if those are not done by top-notch people so that they are more than a list and really discuss works within larger frameworks, they don't work. And I have no system and don't quite know what I don't know. This is very embarrassing to admit all this."

- Learning how to do and keep up with research

-Learning how librarians can help: "It never occurred to me a librarian would/could help!"

- Learning how to keep up: "I don't know what to do to keep up! HELP!"

-Learning how to use information technology in general: "Technologically challenged, I rarely retain what little I learn about cyberspace and so have to waste time being re-instructed one-to-one. I wish my department would lock a little clutch of like(un)minded people in a room (properly equipped) and take us step by step through all the things we must sooner or later learn to become adept Internet researchers, but I bet it would take three mules and a boy to find a time in all our schedules to do so."

-Learning what is available:

-“Lack of knowledge about available resources, particularly new ones, and particularly what might be available on the Internet."

-"I am often concerned that the information might be available, but that I don't know that because the resources are so vast and I don't have enough knowledge about the new databases." 
- Learning to search databases effectively: "I am awkward with doing these complex searches even on the MLA Bibliography, it scares me to death."

- Learning to complete effective searching in all formats:

-“\#1 concern: Am I using it correctly to get out all the information relevant to what I want to know. I often feel there should be more, but it isn't coming out."

-“I am constantly worried that I have not covered enough ground and that an oversight on my part means an important source is neglected."

- Managing information

-Developing an effective, personal system:

-“My office files are bursting. I can't always find what I have. [I manage information] badly, very badly. I've got stacks of unordered stuff everywhere in both home and office."

-“I hunt and peck. I own 3,000 to 4,000 books in three locations (1) office, (2) other campus office, (3) home."

-"I thumbtack things to the wall of my study or my office. Stick them in file folders and then pile the folders in no order."

-Using bibliographic control software effectively:

-“I got an EndNote demo on my sabbatical (the only time I have to learn new stuff) and loved it, but neither my computer at home or school have the memory to make it worthwhile, so I flounder in uncataloged stacks of stuff."

-“I do not know [about bibliographic control software], and I would certainly like to since my system is self-organized and not always efficient."

Problems with their own information center on that perpetual, elusive balance between learning enough about an everchanging information landscape and the demands on their time that preclude that learning. Most instruction mentioned as ineffective was tool based and generic with no focus on the individual scholar in a particular information context.

This question of time recurs so frequently that it bears attention on its own, if only to more fully understand the many and varied limitations that it generates.

- Time to find and get materials

— "As a single working mom, I cannot spend long hours in the library. On the other hand, I still find using Web resources a bit frustrating. Often I can't get online when I need to, and I can't always locate really helpful sites. I am much more likely to go to a bookstore, browse, and buy the books that look relevant or order them from a publisher's catalogue, than any other form of research."

- "Forget instruction. Ineed people to do stuff for me! No time to be instructed or to do it myself. The software has to get much easier before it's worth my while to learn how to, say, make a Web page."

- Time to learn

- "I have to choose between doing research by familiar means or learning new means and not doing research. Time is too limited to do both."

- "I regard my library staff as my allies, eager to be of help and infinitely patient with my repeat requests, but I also feel the panic of fatigue as I try to think when I would actually be able to commit a day or two to tackling these skills."

- Time in general

- "The inordinate amount of time it takes to identify and obtain what I need!"

- “I don't really have as much time as I'd like, so I do what I can and live with frustration."

Reference librarians examining many of these problems will recognize in them, as did some of these scholars, the influence of interdisciplinarity, which multiplies the number of databases, search terms, authorities, and natural language keywords necessary for that fruitful balance of recall and precision that is the goal of in-depth research. Effective strategies and tools were plentifully exemplified as a counterbalance to these problems.

\section{Reports of Productive Strategies and Tools}

Faculty reported an array of successful channels for information seeking, several uses of the library, and a set of thirteen search strategies. Although reported 
separately below, these techniques were almost always described as components of a complex whole rather than as discrete tools used frequently.

\section{Eight Channels for Information}

Gathered in various manners, these information formats were explained by some of the participants as primary information resources, to be sought and explored as critical to their work. None of them, of course, are surprising, but their identification and the context in which they are used are of interest.

- Books

- "Once or twice a year I go to a conference or to a city with a major WS collection bookstore, and I skim (and buy!) a lot of stuff there."

- "I am much more likely to go to a bookstore, browse, and buy the books that look relevant or order them from a publisher's catalogue, than any other form of research."

- Journals

— "I rely on the periodical collection at my school's library for at least $50 \%$ of my journal reading."

—“I take several journals in my field, but I am not satisfied with my current method of reading them, which involves checking for articles of interest and placing them in my (too big) to-do pile."

- Government documents

- "I often need to find up-to-date information from government reportscensus, health, employment stats."

- People

- "People in my network find me resources and they are resources themselves."

- "I asked the librarian to help me learn which microfilm reel I needed on interlibrary loan. I never did get an answer from her. Fortunately, I know someone at another school with access to the electronic database who was able to send me the information I needed to request the right microfilm reel."

- "Our reference librarians are excellent and friendly and convenient."

- Databases
- "I use several online databases (MLA, FirstSearch)."

- "[I] try to remember to use the paper indexes that are still not online."

- Internet

—“I use search engines often, esp. for preliminary background searches."

- Media

- "The Manchester Guardian Weekly, a newspaper to which I subscribe in hard copy."

—“Book review sections of newspapers."

- Gray/primary/archival material

- “It is also clear to me that even if I had unlimited personal resources, I would never be able to collect every title of interest to me, especially since my research is historical. I must rely not only on standard library services at my institution, but also on archives both within and outside my region if I wish to do the most thorough research possible."

When asked to note the qualities of the individuals whom they tend to consult, participants most commonly identified the following: expertise (173 participants); e-mail availability (84); friendship (79); convenience (73); proximity (70); and time available to help (51).

\section{How Libraries Are Used}

Libraries and librarians serve as key resources for a number of WS faculty members. In addition to generic explanations of library use, they note the place of interlibrary loan, reference, user education, student support, and collection development.

- Generic library use

—“University librarians help on all sorts of problems. Right now one of the most important things they're doing is to try to ensure that we continue to have any access at all to paper publications, while assisting with a very painful transition to online publications."

— "Our library is small, but the librarians are very competent and supportive of feminist scholarship."

- Interlibrary loan

—_I rely heavily on library resources to supplement my personal collection of books 
and journals. Although I am in the process of building a personal library that is rich in information on my special fields, my research often takes me far from those fields. It is therefore extremely important to me to be able to access information through interlibrary loan and other such services."

- "I have needed interlibrary loan services for women's studies-related materials often. She got them for me with no problems or queries regarding the content (including articles from off our backs and books such as The Persistent Desire: $A$ Butch/Femme Reader)."

- Reference

—_I need a librarian to ask questions to get me to see my research focus in a different light."

- "Our librarians are very good at helping focus information searches."

- "A way to conceptualize my problem that helped me find reference materials that were useful - talking through the idea and getting her response and knowledge."

- User education

- "I do need help using new technologies and databases, which make me really impatient and grumpy, and many a kind and calm librarian has gotten me out of trouble with them and has taught me about them. Their steady and patient attitude is great and helpful."

- "[The librarian] explained ways to do more sophisticated searches."

— "I have also been impressed with presentations made by our reference librarians at semiannual technology workshops on our campus. The topics over the past six years have covered a wide range, and what I have found most helpful have been the introductions to possible pedagogical uses of such new technological developments as the World Wide Web."

- Student support

- “I work very closely with [name], the social sciences librarian at the University of [place] library who specializes in women's studies... . We plan whole courses and individual assignments together, she team teaches parts of some courses with me, she's on my class listservs, and we have published together on our team effort."

- "I find the reference librarian's support on behalf of graduate students amazingly wonderful and wish it had been there for me in graduate school."

- Collections and resources

— “Our librarians are goddesses. They buy what we ask."

The relationship between research and teaching often covers theoretical perspectives, subject matter, and resources for many of the WS faculty. Librarians who respect the issues under study, know the full range of potential resources, and work with faculty are highly valued.

Finally, participants identified thirteen separate strategies as productive parts of their information-seeking efforts. Some of these grew from library services, but many were their own work.

- Alert services

— "The [library] has a monthly service that supplies bibliographies for every article in my field worldwide."

- "We do have a women's studies librarian who periodically sends all women's studies faculty an e-mail list of new books in the field recently acquired. It is very helpful."

\section{- Trace citations}

- “Most often, I use other people's bibliographies. For example, I read an article on the topic I want to write about. If the article is good and interesting, I read the books/articles in the bibliography."

- "I was writing a review article with 300-400 references. Beginning with a few key authors' names, the librarian followed citations to supply me with hundreds of titles, most of them on target."

- Post questions to discussion lists

— "When I'm getting into a new area, often some kind of a discussion group helps because people can tell me who the people and works are and how they are viewed by others in the field."

- "If I have a question I don't think one of my friends will be able to answer, I'm more likely to use a listserv ... to ask the question than to contact someone I know less well." 
- Browsing

— "As a result of this [reference] encounter, I have begun to use reference room material for not only finding specific material, but also for browsing to encounter new ideas and avenues of research."

- Build a personal collection

- "I also buy books that my library does not own and that I really need, especially if I will either have to photocopy or ILL continually."

-When asked about the uses of their personal collections, respondents noted the following: student support (112), reference (123), research (164), and teaching (186).

- Watch the lists of certain publishers

- "I regularly and carefully read publications fliers from NCTE, Oxford, etc."

- "[I use] publisher catalogues; [I use] ads for new books."

- Use the University of Wisconsin publications in WS

- "I subscribe to Women's Review of Books and Contemporary Sociology, both of which (when I find time to read them) tell me what's being published out there."

- "I find Women's Review of Books and the British journal Radical Philosophy indispensable in reviewing books I can't find time to read."

- Learn to use new tools

- “[Librarians help me learn to use the computers with] general hand-holding as I contemplate my status as technopeasant."

— "Typically, I begin by consulting the MLA online bibliography, then our library's online catalog. Librarians have taught me how to use all of these resources."

- Work with librarians to find/use resources/facts

— "The librarian(s) in our reference department helped me locate [an author's] works and get them on interlibrary loan. What was so significant was their determination to locate sources and their willingness to go beyond their budget, and I know they spent much more time on this than they 'should have.'"
— "I needed to search an online database and sort entries by location. This turned out to be possible with additional commands not in the library-supplied interface, different from the interface librarians used with the database. Of course, none of this was written out, or at least anywhere I could get it. The librarian revealed the commands in the more powerful interface to me."

- Build a personal network

- "I find conferences surprisingly refreshing because they give me a chance to talk to people in my field much more casually as well as to give/hear papers that get me thinking."

- "I tend to contact friends first (I hate asking people I don't know for help!). As an older woman, I wasn't taught as an undergraduate or younger graduate student to network. I had to learn that on my own, and as I'm not a very extroverted personality, my network is small."

- Complete faculty basic responsibilities (research, teach, serve)

- “I volunteer to be on graduate essay prize committees and search committees. That way, one is kept current with new trends in research."

- "[I keep up because] I am active in professional organizations."

- Manage information by authorities and tools

- "I make a bibliography card for each entry and keep [the cards] in alphabetical order by author."

- "I have a nice bibliographic database that I update and from which I routinely build bibliographies for myself and students and colleagues."

- Manage information by personal approach

- "I keep an extensive handwritten index that tracks and cross-references the people and topics that interest me. I can't really do this on a machine because I can't do deep thinking on a machine."

- "I use the method that I call groveling piles, related information in various piles, then I go through them to cull and often rearrange." 
- "I use notecards-have for 18 years-I like the texture of paper and the chance to get away from the computer."

Understanding the sheer array of perspectives on information seeking, retrieval, and organization may encourage a flexible approach to working with individual faculty members. The use of library services, the stages at which library services are useful, the problems in information seeking, and the productive strategies in information seeking delineated by this study add to the growing understanding of interdisciplinary information seeking by faculty in women's studies.

\section{Implications}

Although a great deal remains to be learned about this population's information experiences, the following four implications of this study merit further consideration.

Librarians who are able to partner with, rather than serve, faculty are in a stronger position to support research. They get to know individual research agendas and see the intersections of those agendas with teaching assignments. They know when to model, when to coach, and when to teach so that active learning at the point of need is most effective. They learn about the theories, experts, publishers, Web sites, databases, and issues pertinent to the research agenda, not just a single reference question. Partnership may well require variations in reference department structuring to permit the office visits and on-demand contact that nurtures interpersonal relationships, but the increased effectiveness is strong incentive for change.

One of the sacred cows of academic research is that deep reading in a field is essential to basic competence. Perhaps interdisciplinary scholars need a series of filters more than they need support for deep reading. Librarians understand how to identify, retrieve, and organize information; these scholars often need to develop systems to track current research, find meaningful summaries, and retrieve those pieces that merit deep reading. The understanding of the former can help meet the needs of the latter. Standards for basic competence in an interdisciplinary field may differ from those of a singlediscipline field. Breadth is more critical than depth; connections are more meaningful than detail.

Although much of the research is continuous, many faculty indicated patterns in which intense bursts of activity were required for anything from launching a new project to wrapping up an article for publication. With the classic service model of question and answer, the idea that an extended contact might be possible is simply not considered by many faculty. Librarians might look for means of facilitating on-demand depth work. Many, for example, already offer clinics, research appointments, and personal-librarian-for-an-afternoon options to faculty who can provide sufficient notice. Particularly successful efforts might lead to a charge to fund the service, a charge that could be included in grant applications so that some faculty could pay for the special attention.

Finally, given the information networks formed by many of these scholars, academic librarians might consider serving communities of scholars, in addition to serving individuals. On an individual campus across departmental lines, across the institutions clustered in a geographically convenient region, and even, in special cases, across widely dispersed institutions, the links that librarians could help forge among individuals interested in similar issues could be worthwhile. As one example, a nucleus of faculty interested in the intersections between gender and economics could be identified through research and teaching at the various universities in a metroplex. These faculty members then could be invited to an information colloquium hosted by librarians from each institution. They would be given hands-on instruction in information retrieval and Web site evaluation with additional materials on highly selective, scholarly Web sites, examples of controlled vocabulary issues, and cooperative 
borrowing cards. Although that particular scenario would only work in certain situations, the general principle of fitting into and supporting networks of scholars can be productive.

Interdisciplinary scholars face all of the problems that single-discipline scholars face as well as those caused by the scope and nature of their work. WS scholars, like their colleagues in ethnic and area studies, also face the problems resulting from the often controversial aspects of their social analysis, as well as the problems attendant on all young, rapid-developing fields. When academic librarians understand and meet these needs, they work with an array of tools that will help them serve all faculty.

\section{Librarian Findings}

As mentioned earlier, academic librarians serving WS faculty were invited to share their strategies, tools, tactics, and ideas for best practices. As with the faculty data, these findings are exploratory in nature, not quantitative or representative. Fortytwo librarians from across the United States (including two from other nations) provided a wealth of ideas that might serve to support work in other institutions. Their examples of successful interactions and their advice for new librarians fall into three large categories: general advice, marketing advice, and searching advice.

\section{General Advice}

A few of the general-advice responses centered on a matter of attitude and others focused on more tactical or strategic suggestions.

- Attitude

—Remember that librarians are equal partners with faculty.

-Do not overcommit yourself as it leads to poor performance. Underpromise and overdeliver.

-Recognize and respect the independent nature of many of these scholars.

- Strategies

-Build your credibility as both a librarian and a feminist.
-Never assume that they know the library even if they have been at the institution for some time.

- Be aware of and discuss with them the interdisciplinary nature of their research questions. (Twelve of the 42 respondents made this point.)

- Teach faculty and students alike how to use reference tools that focus on women's issues. (9 respondents)

-Teach faculty how the literature of a field is structured.

-Teach faculty what librarians are capable of doing for and with them. (10 respondents)

- Learn a bit about the issues of WS.

- Tactics

- Involve faculty in the actual search process so you can help them learn as the work progresses.

- Help them manage their Web resources as a means of building their confidence in you and in their own skills.

-Teach electronic information retrieval as a skill rather than squeezing it into a reference interview in bits. (8 respondents)

-Ask colleagues for help, as needed.

- Listen very carefully to the actual question being asked in an effort to identify the information problem. (6 respondents)

These attitudinal suggestions may combine well with the broad strategies and more specific tactics to help foster a long-term connection between librarian and scholar with a focus on problem solving and faculty development.

\section{Marketing Advice}

Exactly half the librarians emphasized the value of building relationships with the WS community through services and marketing. Given the lack of respect for their research and teaching that is sometimes evinced by their colleagues, WS faculty often look carefully for signs of interest in their subject matter. Biologists' reference questions, for example, are seldom met with skepticism, but WS faculty deal with it often enough to seek out supportive colleagues who do not require a basic educa- 
tion in feminist theory as a prerequisite to discussion. ("I tend to get questions at committee meetings, in the halls of campus buildings, in the parking lot, or even in the supermarket-anywhere but the library. I suspect many WS researchers won't even approach a librarian unless they know of their interest. And people tend to go to those they know.") Marketing, therefore, is presented in terms of building relationships based on mutual respect and interest. These librarians did not propose marketing as a simple campaign of informing faculty of library services; rather, they propose marketing of a more thoughtful, engaging, and mutual nature. The following suggestions move this theory of integrated, relationship-based marketing into the concrete and practical:

- Inform faculty. ("I find that teaching faculty need to be educated in what librarians can do for them. I note the tendency to talk among themselves on listservs, etc., to get ideas for course readings, etc., when they could be much better served by consulting the librarian.")

-Put out a newsletter, paper and/or digital, on library resources and services.

-Mail annual, personal letters with specific suggestions regarding information needs on a large scale, such as ongoing courses or a research agenda.

-Put out alerts on new acquisitions of interest.

-Develop guides, bibliographies, Web pages, and portals on specific topics within the curriculum.

-When faculty come for a job interview, get time on their schedule to give them a tour of the library. When faculty are hired, follow up that tour with personal contacts offering to support their coming coursework and research.

- Involve and work with faculty

-Volunteer for their events (e.g., be a panel moderator for them).

-Invite them to library events and set up events around their work.

-Invite them to serve on library boards and committees. sible.
-Urge them to order materials.

-Look for research opportunities that would let you work with faculty or study their information-seeking problems.

- Listen to faculty

-Attend WS departmental and committee meetings, when possible.

-Attend their research forums to learn about their issues and areas.

-Read campus and local newspapers to keep up with immediate issues of interest to the local WS community.

- Take a basic, introductory class in WS if the entire field is new to you.

- Respond to faculty

-Exchange contact information at an in-person meeting.

-Participate in discussion lists.

-Write articles for the WS newsletter.

- Teach their students as a conduit to meeting their needs.

-Make yourself fully available and be gracious when contacted.

- Respond positively to all their forays into the library.

Obviously, this level of marketing requires a great deal of time, energy, and commitment. Even an abbreviated version of it may be beyond the resources of many libraries. Nevertheless, the approach builds on a viable perspective, namely that marketing built on an interpersonal relationship opens the door to more deeply engaged reference service.

\section{Searching Advice}

Finally, several librarians explained that searching skills lay at the heart of service to the women's studies community. Seventeen recommended that librarians think broadly, creatively, and flexibly about multiple sources and strategies. ("Be creative. As an interdisciplinary area, WS requires thinking very broadly at times, making connections between seemingly unrelated possible resources, coming up with innovative ways to get at information either not indexed at all or not indexed well.") Twenty-one found that a careful combination of traditional and women-centered tools was needed to conduct the "detective work" often needed 
by WS faculty. ("Remember how interdisciplinary the area is. Try a variety of databases; remember the print indexes that we still have. Flexibility and a variety of approaches are often necessary.") Finally, eighteen librarians emphasized the need to learn about as many alternative reference tools as possible, especially those that focused on women's issues. Those three broad strategies were underpinned by an array of specific tactics:

- Look for the bias in controlled vocabulary.

- Look for name changes in authors and subjects.

- Look for alternative paths to reach unindexed material, such as experts.

- Look for alternative statistics sources, such as grassroots organizations that gather data not collected by governments.

- Look for alternative biographical sources, such as organization, social, and political histories.
- Use printed indexes for older material, but note the changes in controlled vocabulary over time.

- Learn about and use the subject headings concerning women.

- Learn about and use the classifications concerning women.

- Follow and use WMST-L, as needed.

- Use the University of Wisconsin publications from the WS library.

- Develop good interlibrary loan skills to counter the problems caused by short book runs and out-of-print books.

As several librarians noted, the recovery work of the field is far from complete, with a great deal of women's writings, work, and accomplishments still undocumented or poorly indexed. These tactics, however, provide a set of tools that can supplement the best work of traditional reference, which is more rooted in mainstream publications and information dissemination patterns.

\section{Notes}

1. Julie Klein, "Interdisciplinary Needs: The Current Context," Library Trends 45 (fall 1996): 134-54.

2. For the initial report, see: Lynn Westbrook, "Reference Support for Interdisciplinary Scholars: Resources for Working with Women's Studies Faculty," Conference Proceedings of the Association of College and Research Libraries National Conference, March 15-18 2001, Denver, Colorado (Chicago: Association of College and Research Libraries, 2001), 265-70.

3. This section, part of the literature review, and the section on data gathering, naturally echo some parts of the initial report on the first segment of the study and are included with the gracious permission of ACRL, which published the first study in its conference proceedings. See Westbrook, "Reference Support for Interdisciplinary Scholars."

4. Marcia Bates, "Learning about the Information Seeking of Interdisciplinary Scholars and Students," Library Trends 45 (fall 1996): 155-64; Carole L. Palmer and Laura J. Neumann, "The Information Work of Interdisciplinary Humanities Scholars: Exploration and Translation," Library Quarterly 72, no. 1 (2002): 85-117; Don Spanner, "Border Crossings: Understanding the Cultural and Informational Dilemmas of Interdisciplinary Scholars," Journal of Academic Librarianship 27 , no. 5 (2001): 352-60.

5. Lynn Westbrook, Interdisciplinary Information Seeking in Women's Studies (Jefferson, N.C.: McFarland, 1999), 113-116.

6. Judith Palmer, "Information Work at the Boundaries of Science," Library Trends 45 (fall 1996): 165-91.

7. Kristin Gerhard, Trudi Jacobson, and Susan Williamson, "Indexing Adequacy and Interdisciplinary Journals," College and Research Libraries 54, no. 2 (1993): 125-33. 29.

8. Judith Palmer, "Scientists and Information," Journal of Documentation 47 (June 1991): 105-

9. Scott Stebelman, "Analysis of Retrieval Performance in Four Cross-Disciplinary Databases," College and Research Libraries 55 (Nov. 1994): 562-67.

10. Marilyn Boxer, "Unruly Knowledge: Women's Studies and the Problem of Disciplinarity," NWSA Journal 12 (summer 2000): 119-29.

11. L. J. B. Mote, "Reasons for the Variations in the Information Needs of Scientists," Journal of Documentation 18 (Dec. 1962): 169-75. 
12. Sue Searing, “A Quiet Revolution," Women's Review of Books 6 (Feb. 1989): 19.

13. Mary Ellen Capek, "Wired Words," in Alternative Library Literature 1986/87, ed, Sanford Berman and James Danky (Jefferson, N.C.: McFarland, 1988), 25; Sanford Berman, "Foreword," in On Equal Terms: A Thesaurus for Nonsexist Indexing and Cataloging, ed. Joan Marshall (New York: Neal-Schuman, 1977).

14. Joyce Duncan Falk, "Humanities," in Women Online, ed, Steven Atkinson and Judith Hudson (New York: Haworth, 1990); Suzanne Hildenbrand, “Women's Studies Online," Research Quarterly 26, no. 1 (1986): 63-74.

15. Sarah Pritchard, "RLG Conspectus Women's Studies," in Women's Studies Collection Development Policies (Chicago: Women's Studies Section, Association of College and Research Libraries, ALA, 1990), Appendix C, 1-32; Kristin Gerhard, "Challenges in Electronic Collection Building in Interdisciplinary Studies," Collection Management 25, no. 1/2 (2000): 51-65.

16. Ellen Broidy, "Bibliographic Instruction in Women's Studies," in Conceptual Frameworks for Bibliographic Education, ed, Mary Reichel and Mary Ann Ramey (Littleton, Colo.: Libraries Unlimited, 1987), 86-96; Sarah Pritchard, "Linking Research, Policy, and Activism," Reference Librarian 20 (1987): 89-103.

17. Kristin Gerhard, Mila Su, and Charlotte Rubens, "An Empirical Examination of Subject Headings for Women's Studies Core Materials," College and Research Libraries 59, no. 2 (1998): 130-38; Margaret Rogers, "Are We on Equal Terms Yet? Subject Headings Concerning Women in LCSH, 1975-1991," Library Resources and Technical Services 37 (Apr. 1993): 181-96.

18. Susan Searing, "Meeting the Information Needs of Interdisciplinary Scholars: Issues for Administrators of Large University Libraries," Library Trends 45 (fall 1996): 315-42.

19. Westbrook, Interdisciplinary Information Seeking in Women's Studies.

20. See Westbrook, "Reference Support for Interdisciplinary Scholars," for more complete details on the methodology.

21. For more information, contact WMST-L-request@umdd.umd.edu.

22. "Survey Info Needed," NWSAction 9 (spring 1998): 17.

23. Bates, "Learning about the Information Seeking of Interdisciplinary Scholars and Students"; Gerhard, Su, and Rubens, "An Empirical Examination of Subject Headings for Women's Studies Core Materials"; Westbrook, Interdisciplinary Information Seeking in Women's Studies.

24. Not every respondent answered every single question, so some of the totals do not equal 215.

25. Percentages are rounded off, so their totals do not always equal one hundred.

26. Elizabeth Futas, "Communication and Information Patterns in the Emerging Interdiscplinary Area of Women's Studies" (Ph.D. diss., Rutgers University, 1980). 4.

27. "Research Study on Women's Studies Library Services," WSS Newsletter 13 (spring 1998):

28. Lynn Westbrook, "Qualitative Research," in Basic Research Methods for Librarians, 3rd ed., ed. Ronald Powell (Greenwich, Conn.: Ablex, 1997): 143-63; see also, Yvonna Lincoln and Egon Guba, Naturalistic Inquiry (Newbury Park, CA.: Sage, 1985).

29. To facilitate reading, abbreviations in these quotations have been completed (e.g., "gov't doc libn" becomes "government documents librarian") and minor typing errors corrected. Any potentially identifying information (e.g., the name of an institution) has been removed.

30. For more on the concept of interdisciplinarity, see: Julie Klein, Interdisciplinarity: History, Theory, and Practice (Detroit, MI: Wayne State University Press, 1990); ——, "Interdisciplinary Needs: The Current Context," Library Trends 45, no. 2 (1996): 134-54; and ——, Crossing Boundaries: Knowledge, Disciplinarities, and Interdisciplinarities (Charlottesville, Va.: University Press of Virginia, 1996). 